\title{
CARACTERIZAÇÃO DO MATERIAL COMBUSTÍVEL E SIMULAÇÃO DO COMPORTAMENTO DO FOGO EM EUCALIPTAIS NO LITORAL NORTE DA BAHIA, BRASIL
}

\author{
Benjamin Leonardo Alves White ${ }^{1}$, Genésio Tâmara Ribeiro ${ }^{2}$, Rosemeri Melo Souza ${ }^{3}$ \\ ${ }^{1}$ Biólogo, M.Sc., Laboratório de Geoecologia e Planejamento Territorial, UFS, São Cristóvão, SE, Brasil - benjmk@ hotmail.com \\ ${ }^{2}$ Eng. Florestal, Dr., Laboratório de Entomologia, UFS, São Cristóvão, SE, Brasil - genesiotr@ hotmail.com \\ ${ }^{3}$ Geógrafa, Dr ${ }^{a}$., Laboratório de Geoecologia e Planejamento Territorial, UFS, São Cristóvão, SE, Brasil - rome@ufs.br
}

Recebido para publicação: 07/08/2013 - Aceito para publicação: 17/10/2013

Eucalyptus é o gênero florestal plantado em maior quantidade no Brasil, sendo sua madeira utilizada, principalmente, para a produção de celulose. Incêndios florestais dentro de plantações dessas espécies acabam por danificar ou consumir a matéria-prima, gerando prejuízos de ordem econômica. $\mathrm{O}$ presente trabalho teve por objetivo caracterizar o material combustível superficial nos povoamentos de eucalipto pertencentes à empresa Copener Florestal Ltda., localizados no litoral norte da Bahia, e, por conseguinte, determinar o comportamento do fogo em diferentes cenários com base em simulações computacionais utilizando o BehavePlus Fire Modeling System. Para tal, foram realizadas 40 amostragens destrutivas de coleta de material combustível em 5 distintos povoamentos de 6 anos. A espessura do leito foi definida por meio de transectos linha, e a velocidade do vento, com base em dados da estação meteorológica Salgado. Demais dados foram obtidos através de consulta à literatura. Os povoamentos de eucalipto apresentaram em média 11,31 t/ha de material combustível, espessura do leito média de $5,94 \mathrm{~cm}$ e velocidade do vento média de $4,45 \mathrm{~km} / \mathrm{h}$. Com base nas simulações, foi definido que apenas no cenário de alto perigo é essencial a utilização de equipamentos de grande porte para combate ao fogo.

Palavras-chave: Incêndios florestais; proteção florestal; silvicultura.

\begin{abstract}
Characterization of the understory fuel load and fire behavior simulation in eucalyptus plantations in north coast of Bahia, Brazil. Currently, eucalyptus is the most planted forest genus in Brazil, being its wood used mainly for the production of cellulose. Forest fires in plantations of these species eventually damage or consume the raw material, generating economic losses. This work aims to characterize the surface fuel load in eucalypt plantation of the Copener Florestal Ltda. company, located on the northern coast of Bahia, and, therefore, determine the fire behavior in different scenarios based on computer simulations using the BehavePlus Fire Modeling System. In order to that, we conducted 40 destructive sampling in 05 different 06 years old stands. The fuel bed depth was determined through transect line methodology, and the wind speed was based on data from the Salgado weather station. Other data were obtained from the literature. The eucalyptus plantations had on average $11.31 \mathrm{t} /$ ha fuel load, $5.94 \mathrm{~cm}$ of fuel bed depth average, and average wind speed of 4.45 $\mathrm{km} / \mathrm{h}$. Based on the simulations it was defined that only in the scenario of high risk it is essential to use large equipment for firefighting. In low and medium hazard scenarios fire can be extinguished by people using hand equipments.

Keywords: Forest fire; forest protection; silviculture.
\end{abstract}

\section{INTRODUÇÃO}

O eucalipto é a espécie florestal mais usada nos programas de reflorestamento no Brasil, em razão de suas características de rápido crescimento e boa adaptação às condições edafoclimáticas existentes no país. Graças ao clima favorável do Brasil e ao avanço alcançado pelas empresas em 
pesquisa e tecnologia florestal, o eucalipto normalmente é colhido até 7 anos para a produção de celulose, quando atinge até 35 metros de altura (SOCIEDADE BRASILEIRA DE SILVICULTURA (SBS), 2009).

Nos reflorestamentos de eucalipto, a alta produtividade e concentração de biomassa representam um grande perigo para ocorrência de incêndios florestais de grande porte. Nessas áreas, o fogo costuma ser veementemente temido, já que existe um alto valor econômico associado à venda de madeira. $\mathrm{O}$ fogo não necessariamente irá consumir toda a biomassa viva, entretanto, a depender da sua intensidade, pode danificar as árvores a tal ponto que a madeira se torne desqualificada para a produção de celulose.

Segundo Santos et al. (2006), entre 1998 e 2002, no Brasil, foram registrados 5832 incêndios apenas em plantações de Eucalyptus spp. O valor representa $30 \%$ de todos os incêndios, em todos os tipos de vegetação, registrados no Brasil. Esses incêndios responderam por uma área queimada de 13561,65 hectares ( $16 \%$ de toda a área queimada no Brasil no período supracitado).

Para melhor compreender e combater os incêndios em povoamentos de eucalipto, é necessário o conhecimento das características básicas do combustível. A quantidade de material combustível, de acordo com Soares e Batista (2007), está diretamente relacionada à intensidade de calor liberado pelo fogo. De acordo com Rego e Botelho (1990), a facilidade de ignição e a velocidade de propagação do fogo vão depender, dentre outros fatores, dos tipos de materiais combustíveis presentes para queima. $\mathrm{O}$ conteúdo de umidade do material combustível é a mais importante propriedade que controla a inflamabilidade dos combustíveis (SOARES; BATISTA, 2007), e a espessura do manto está diretamente relacionada ao comprimento das chamas e à velocidade de propagação do fogo (ROTHERMEL, 1972).

Existem modelos matemáticos que descrevem o comportamento do fogo que vêm sendo desenvolvidos desde a década de 40. O modelo mais aceito, e mais citado na literatura, é o modelo de Richard C. Rothermel (1972) (WELLS, 2008). Esse modelo se constitui numa ferramenta que é utilizada até os dias atuais pelo Departamento de Agricultura Norte-Americano (USDA). O sistema proposto por Rothermel serviu de base para o desenvolvimento de diversos programas computacionais, como o "Behave" (BURGAN et al., 1984), o "BehavePlus" (ANDREWS et al., 2003) e o "Farsite" (FINNEY, 1998), que, além de indicar as condições de combustão, oferecem uma previsão do comportamento do fogo, como, por exemplo, intensidade, comprimento das chamas, direção do incêndio, área consumida pelo fogo e energia calorífica liberada por unidade de área, entre diversas outras variáveis.

Estudos envolvendo essas ferramentas costumam ser desenvolvidos em países como Estados Unidos, onde, de acordo com Barrett et al. (2000), 85\% dos gestores de fogo prescrito no oeste do país utilizam-se de tais softwares. Já no Brasil o uso de tais ferramentas e estudos envolvendo as mesmas são muito raros. De acordo com White et al. (2013b), apenas alguns poucos estudos de simulação do comportamento do fogo realizados no Brasil são encontrados na literatura, como, por exemplo, White et al. (2013a), no Parque Nacional Serra de Itabaiana, Sergipe, Mistry e Berardi (2005), no Planalto Central, e Hoffmann et al. (2012), em áreas de cerrado e floresta na região sul e central.

O modelo matemático de Rothermel e os programas computacionais desenvolvidos com base nesse modelo requerem como variáveis de entrada dados acerca das características da vegetação em questão. Portanto, o presente trabalho teve como objetivo caracterizar o material combustível nos povoamentos de eucalipto do litoral norte da Bahia e, em seguida, realizar simulações em diferentes cenários, com o objetivo de descrever o provável comportamento do fogo.

Com base nos resultados advindos das simulações, será possível traçar um efetivo plano de combate ao fogo para cada cenário de perigo, aprimorando, assim, o procedimento de combate e minimizando as perdas econômicas oriundas dos incêndios.

\section{MATERIAL E MÉTODOS}

\section{Caracterização da área de estudo}

A área de estudo está localizada no litoral norte da Bahia, entre as latitudes $11^{\circ} 15^{\prime} \mathrm{S}$ e $12^{\circ} 30^{\prime} \mathrm{S}$ e longitude $37^{\circ} 30^{\prime} \mathrm{W}$ e $38^{\circ} 45^{\prime} \mathrm{W}$, com elevações entre 0 e $300 \mathrm{~m}$. Faz parte da empresa Copener Florestal Ltda., que possui um total aproximado de 100.000 ha de plantações de eucalipto, sendo a maioria delas resultantes do cruzamento entre Eucalyptus grandis (Hill ex. Maiden) e Eucalyptus urophylla (S. T. Blake) (Figura 1). 


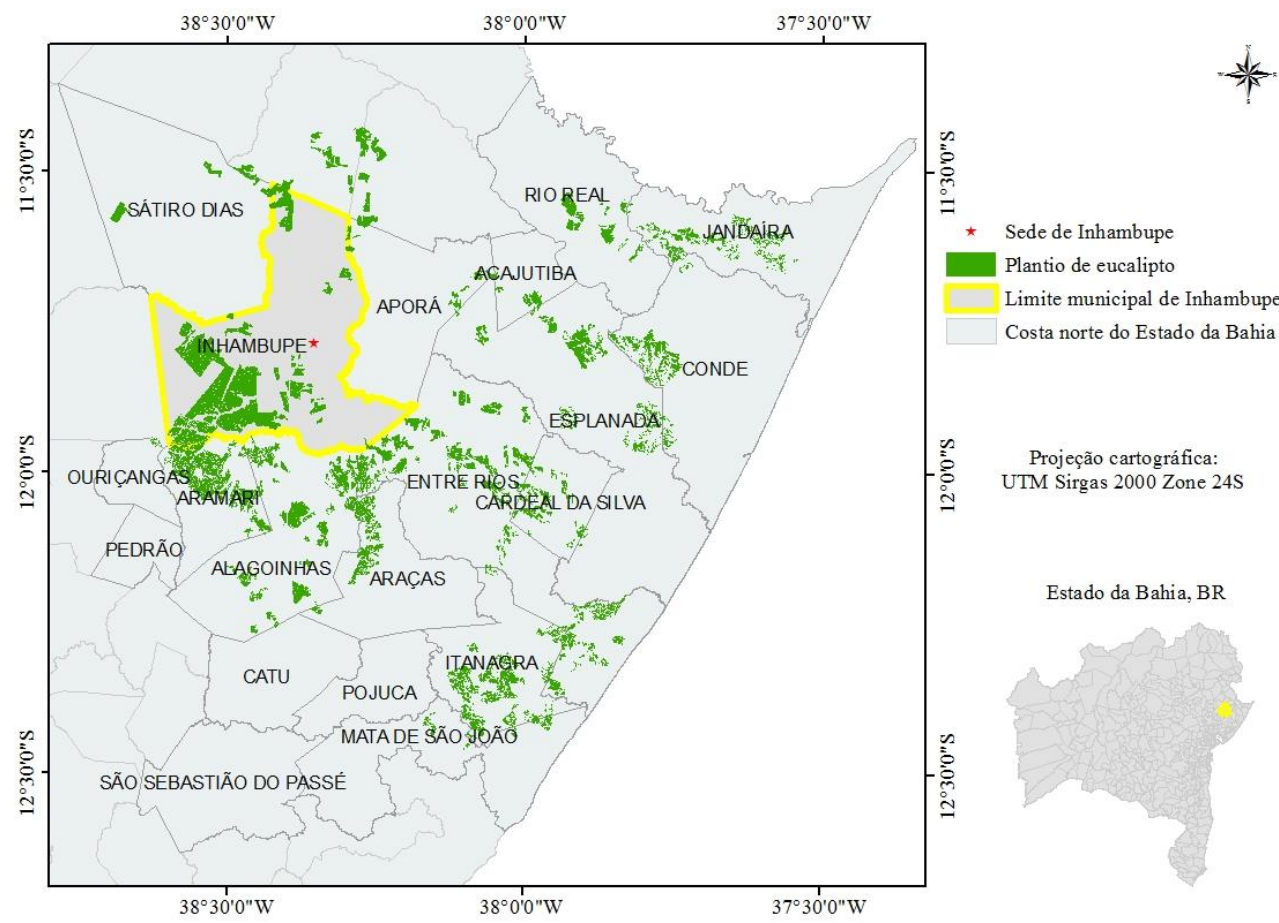

Figura 1. Localização dos povoamentos de eucalipto da empresa Copener Florestal Ltda. no litoral norte da Bahia, Brasil.

Figure 1. Localization of the Eucalyptus plantations of the Copener Florestal Ltda. company, located in the north coast of Bahia, Brazil.

\section{Quantificação do material combustível}

Foram demarcadas 40 parcelas aleatórias de 1 x $1 \mathrm{~m}$ dentro de cinco distintos povoamentos de eucalipto com 6 anos de idade. Tal idade foi estabelecida em função de que o processo de colheita nos eucaliptais da área de estudo costuma ocorrer em povoamentos com cerca de 6 anos, e pelo fato de que, quanto maior a idade do povoamento, maior o acúmulo de material combustível e, consequentemente, maior o perigo de ocorrência de incêndios de grande porte (SOUZA et al., 2003). As coletas foram realizadas durante a estação seca (novembro 2011 - março 2012). O número de parcelas foi calculado de acordo com a metodologia de amostragem sequencial, com um limite de erro de $10 \%$ a um nível de probabilidade de $95 \%$.

A quantificação do material combustível foi realizada através do método de amostragem destrutiva, em que toda a biomassa vegetal até $1,8 \mathrm{~m}$ de altura (limite do material combustível superficial) foi coletada, separada e teve sua massa determinada. A carga do material combustível foi quantificada para as seguintes classes:

A) Material combustível vivo:

- Material herbáceo (MVHerb): plantas que possuem a consistência e porte de erva. Ex: gramíneas e samambaias.

- Material verde lenhoso (MVL): inclui a folhagem e os pequenos ramos dos arbustos vivos. São materiais cujo diâmetro é menor ou igual a $0,7 \mathrm{~cm}$.

B) Material combustível morto (seco):

- MS1: material seco com diâmetro menor ou igual a $0,70 \mathrm{~cm}$.

- MS2: material seco com diâmetro entre 0,71 e $2,50 \mathrm{~cm}$.

- MS3: material seco com diâmetro entre 2,51 e 7,60 cm. 
As metodologias utilizadas para coletar, categorizar e determinar a massa foram baseadas em trabalhos de Rothermel (1972) e Brown et al. (1982). Todo o material combustível morto foi classificado nas classes de diâmetro com auxílio de um paquímetro. Os combustíveis mortos maiores que 7,60 cm e verdes lenhosos maiores que $0,70 \mathrm{~cm}$ de diâmetro não foram coletados, devido a não contribuírem com a propagação do fogo superficial, de acordo com o modelo de Rothermel (1972).

Após a operação de coleta, classificação e determinação da massa, foram retiradas subamostras representativas de cada classe (uma subamostra de aproximadamente $100 \mathrm{~g}$ de cada classe de material combustível dentro de cada parcela), que, depois de quantificadas, foram acondicionadas em sacos plásticos e levadas ao laboratório para secagem e posterior determinação do teor de umidade e massa da matéria seca ao forno. A secagem foi feita na estufa, a uma temperatura de $\pm 100{ }^{\circ} \mathrm{C}$, durante 24 horas, conforme recomendado por Matthews (2010).

Além dos valores médios da carga do material combustível em função da classe de diâmetro, foram definidos os percentis de 10 e $90 \%$, para a simulação do comportamento do fogo em cenários de baixo e alto perigo, respectivamente.

\section{Determinação da espessura do leito do material combustível}

A espessura do leito do material combustível foi obtida com o objetivo de definir a densidade do material combustível (fuel bed bulk density), que consiste na carga total do material combustível seco por volume do leito do material combustível $\left(\mathrm{kg} / \mathrm{m}^{3}\right)$.

Ao total, foram demarcados 132 pontos no interior dos povoamentos de seis anos de idade. A metodologia utilizada foi a do transecto linha, em que, a cada $1 \mathrm{~m}$, foi marcado um ponto e definido, com auxílio de uma régua, o valor da espessura da manta. Além do valor médio, também foram definidos os percentis de 10 e $90 \%$, para as simulações de baixo e alto perigo, respectivamente.

\section{Análise estatística}

Toda a análise estatística foi efetuada com auxílio do programa JMP 7.0. A princípio, o teste da análise de variância (ANOVA) foi realizado para verificar se existia diferença significativa entre a carga e a espessura do manto dentro de distintos povoamentos. O nível de significância adotado foi de 5\%. Posteriormente, foram definidos os valores médios e desvio padrão para a carga de todas as classes de material combustível, assim como para a espessura da manta morta. A densidade do material combustível foi definida com base no valor médio da carga do material combustível e da espessura da manta.

\section{Simulando o comportamento do fogo}

Para tal, foi utilizado o software BehavePlus Fire Modeling System (5.0.5). Utilizando-se os dados coletados em campo relativos à carga do material combustível e à espessura do leito, foram construídos três modelos customizados de material combustível (baixo, médio e alto perigo), a fim de simular a velocidade de propagação do fogo, a intensidade da linha do fogo e o comprimento das chamas, com base nos modelos matemáticos de propagação do fogo superficial de Rothermel (1972) e Byram (1959).

Valores estáticos necessários para a realização das simulações referentes às variáveis área superficial pelo volume, umidade de extinção e poder calorífero do material combustivel foram obtidos na literatura (FERNANDES et al., 2011; SCOTT; BURGAN, 2005) (Tabela 1).

Tabela 1. Valores encontrados na literatura referentes à área superficial pelo volume, umidade de extinção e poder calorífero do material combustível para povoamentos de eucalipto.

Table 1. Values in the literature for surface area by volume ratio, moisture of extinction and fuel heat content for Eucalyptus plantations.

\begin{tabular}{lcc}
\hline Parâmetro & Valor & Referência \\
\hline Área superficial pelo volume do material de $1 \mathrm{~h}\left(\mathrm{~m}^{2} / \mathrm{m}^{3}\right)$ & 4200 & Fernandes et al. $(2011)$ \\
Área superficial pelo volume do material vivo herbáceo $\left(\mathrm{m}^{2} / \mathrm{m}^{3}\right)$ & 4921 & Scott e Burgan $(2005)$ \\
Área superficial pelo volume do material vivo lenhoso $\left(\mathrm{m}^{2} / \mathrm{m}^{3}\right)$ & 4921 & Scott e Burgan (2005) \\
Umidade de extinção do material combustível morto $(\%)$ & 25 & Scott e Burgan (2005) \\
Energia calorífera do material combustível morto $(\mathrm{kJ} / \mathrm{kg})$ & 21000 & Fernandes et al. $(2011)$ \\
Energia calorífera do material combustível vivo $(\mathrm{kJ} / \mathrm{kg})$ & 21000 & Fernandes et al. $(2011)$ \\
\hline
\end{tabular}


A variável umidade do material combustível foi definida de acordo com três distintos cenários já padronizados por Scott e Burgan (2005) (Tabela 2). A variável velocidade do vento na altura das chamas, que compreende a velocidade do vento média durante a propagação do fogo a uma altura aproximada de 1,8 metros (ANDREWS, 2009), foi obtida com base nos registros médios diários do anemômetro, instalado na mesma altura, da estação meteorológica "Salgado", para o período de 01/01/2002 a 30/01/2010, compreendendo um total de 2922 dias. Essa estação está localizada na cidade de Inhambupe (latitude $11^{\circ} 50^{\prime} 42^{\prime \prime} \mathrm{S}$, longitude $38^{\circ} 22^{\prime} 02^{\prime \prime} \mathrm{W}$ ), a uma altitude de $233 \mathrm{~m}$. A inclinação do terreno utilizada para todas as simulações foi de $0^{\circ}$.

Tabela 2. Cenários padronizados de umidade do material combustível de acordo com Scott e Burgan (2005).

Table 2. Scott and Burgan (2005) fuel moisture scenarios.

\begin{tabular}{lccc}
\hline \multirow{2}{*}{ Material combustível } & \multicolumn{3}{c}{ Cenários de teor de umidade (\%) } \\
& D2 (baixo) & D3 (moderado) & D4 (alto) \\
\hline Morto de $1 \mathrm{~h}$ & 6 & 9 & 12 \\
Morto de $10 \mathrm{~h}$ & 7 & 10 & 13 \\
Morto de $100 \mathrm{~h}$ & 8 & 11 & 14 \\
Vivo herbáceo & 60 & 90 & 120 \\
Vivo lenhoso & 90 & 120 & 150 \\
\hline
\end{tabular}

\section{RESULTADOS E DISCUSSÃO}

\section{Determinação da carga do material combustível}

Foram coletados ao todo $44,107 \mathrm{~kg}$ de material combustível seco nas 40 parcelas de $1 \mathrm{~m}^{2}$, o que correspondeu a uma média de 11,31 t/ha. O teste ANOVA evidenciou que não existiu diferença significativa entre a carga total de material combustível dentro dos povoamentos $(F=0,1 ; p=0,75)$.

Analisando as classes individualmente, a MS1 contribuiu com a maior parte do material combustível (70\%), seguida pela classe MS2 (24\%), MVHerb (3\%), MS3 (2\%) e, por fim, MVL (1\%) (Tabela 3).

Tabela 3. Carga média, percentil de $10 \%$ e percentil de $90 \%$ do material combustível presente nos povoamentos de eucalipto no litoral norte da Bahia.

Table 3. Mean, $10 \%$ percentile, and $90 \%$ percentile of the fuel load in Eucalyptus plantations of the Bahia north coast.

\begin{tabular}{lccc}
\hline Classe do material combustível & Carga média (t//ha) & Percentil 10\% (t/ha) & Percentil 90\% (t/ha) \\
\hline MS1 & $8,03( \pm 5,19)$ & 2,93 & 16,13 \\
MS2 & $2,74( \pm 1,56)$ & 1,20 & 5,05 \\
MS3 & $0,17( \pm 0,62)$ & 0,00 & 0,21 \\
MVHerb & $0,29( \pm 0,66)$ & 0,00 & 0,56 \\
MVL & $0,08( \pm 0,30)$ & 0,00 & 0,10 \\
TOTAL & $11,31( \pm 6,49)$ & 4,13 & 22,05 \\
\hline
\end{tabular}

Nota: ( \pm ) desvio padrão.

Souza et al. (2003) determinaram a carga total média de material combustível superficial e a proporção entre as distintas classes em povoamentos de Eucalyptus dunnii Maiden, em Três Barras (SC). De acordo com os autores, em povoamentos de 4,5 anos de idade, a carga total média foi de 10,77 t/ha, enquanto que em povoamentos de 6,5 anos o valor médio subiu para 17,22 t/ha. Ainda de acordo com os mesmos autores, a classe MS1 respondeu por $72 \%$ e $71 \%$ do aporte total do material combustível nas idades de 4,5 e 6,5 anos, respectivamente. A classe MS2, $13 \%$ e $20 \%$, a classe MS3, $1 \%$ e $0 \%$, e as classes MHerb e MVL, juntas, responderam por $14 \%$ e $9 \%$, para as respectivas idades. Ribeiro e Soares (1998) também determinaram a carga média de material combustível e a sua proporção entre as classes em povoamentos de 10 anos de Eucalyptus viminalis Labill no município de Três Barras, Santa Catarina. De acordo com os autores, os povoamentos apresentaram entre 24,25 e $29,96 \mathrm{t} / \mathrm{ha}$, sendo que $85,5 \%$ do material foi classificado como MS1, 9,5\% na classe de material vivo de diâmetro inferior a $0,6 \mathrm{~cm}$ 
(MVL + MHerb), 4,7\% na classe MS2 e 0,3\% na classe MS3. Stangerlin et al. (2007) afirmaram que a quantidade de material combustível presente em um povoamento de Eucalyptus grandis de 12 anos de idade na cidade de Santa Maria, RS, foi de 24,59 t/ha, sendo 81\% do material classificado como MS1, $18 \%$ MS2 e $1 \%$ raízes, sementes e material verde.

Percebe-se que existe uma tendência de a quantidade de material combustível aumentar de acordo com o aumento da idade do povoamento. Conforme Souza et al. (2003), os contínuos incrementos da carga total de combustível demonstram que o acúmulo de material combustível superficial, inclusive em idades mais avançadas (10 anos), ainda se sobrepõe à sua decomposição, potencializando o perigo de incêndios de maior porte em povoamentos mais antigos. Estudos australianos sugerem que, em florestas esclerófilas de eucalipto com cobertura de copa de $50 \%$ ou mais, o acúmulo de material combustível é crescente até os 10 primeiros anos de idade, atingindo equilíbrio com uma carga média de $15 \mathrm{t} / \mathrm{ha}$ (BROOKS et al., 2004). Já em áreas com um sub-bosque bem desenvolvido, a carga de material combustível pode continuar aumentando por mais de 25 anos (TOLHURST; CHENEY, 1999). Fernandes et al. (2011) afirmaram que, em povoamentos de Eucalyptus globulus Labill, em Portugal, os povoamentos atingiram o patamar de $95 \%$ da carga máxima de material combustível após os oito primeiros anos.

O procedimento de colheita na área de estudo, que costuma ocorrer em povoamentos com seis anos de idade, impede a continuidade de acumulação de material combustível, sendo os dados de carga de material combustível encontrados neste trabalho próximos aos valores máximos possíveis para os povoamentos da empresa Copener Florestal Ltda.

\section{Espessura do leito do material combustível}

Com base em 132 medições, o valor médio da espessura do leito foi de $5,67 \mathrm{~cm}$. Através da análise de variância, constatou-se que não houve diferença significativa na espessura do manto entre os distintos povoamentos $(\mathrm{F}=2,08 ; \mathrm{p}=0,15)$.

Ribeiro e Soares (1998), analisando a espessura do manto, encontraram valores médios entre 11,48 e 36,05 cm para distintos povoamentos de 10 anos de Eucalyptus viminalis no município de Três Barras, Santa Catarina. Já Gilroy e Tran (2006) encontraram valores médios de 1,7 cm para povoamentos de Eucalyptus racemosa Cavanilles no sudeste do estado de Queensland, Austrália.

Com base nos valores médios e nos percentis de 10 e $90 \%$ da carga de material combustível e da espessura do leito, foi possível determinar a densidade do material combustível (fuel bed bulk density) para os respectivos cenários (Tabela 4).

Tabela 4. Espessura do leito, carga e densidade do material combustível média, percentil de $10 \%$ e percentil de $90 \%$ para povoamentos de eucalipto do litoral norte da Bahia.

Table 4. Mean, $10 \%$ percentile, and $90 \%$ percentile for the fuel bed depth, fuel load and fuel bed bulk density for Eucalyptus plantations of the Bahia north coast.

\begin{tabular}{lccc}
\hline & Valor médio & Percentil 10\% & Percentil 90\% \\
\hline Espessura do leito $(\mathrm{cm})$ & $5,67( \pm 3,67)$ & 2,00 & 10,90 \\
Carga do material combustível $(\mathrm{t} / \mathrm{ha})$ & $11,31( \pm 6,49)$ & 4,13 & 22,05 \\
Densidade do material combustível $\left(\mathrm{kg} / \mathrm{m}^{3}\right)$ & 19,95 & 20,65 & 20,23 \\
\hline
\end{tabular}

Fernandes et al. (2011) determinaram a densidade do material combustível em povoamentos de Eucalyptus globulus, em Portugal, como sendo de $23,6 \mathrm{~kg} / \mathrm{m}^{3}$. Ainda de acordo com os mesmos autores, em áreas pós-desbaste a densidade subiu para $34,4 \mathrm{~kg} / \mathrm{m}^{3}$.

\section{Simulando o comportamento do fogo}

Determinando a velocidade do vento

Com base em 2922 registros da velocidade do vento média diária (01/01/2002 a 30/01/2010) na área de estudo, a velocidade média do vento foi de $4,45 \mathrm{~km} / \mathrm{h}$. Os percentis de $10 \%$ e $90 \%$ foram 2,86 e $6,07 \mathrm{~km} / \mathrm{h}$, respectivamente (Figura 2).

Descrevendo o comportamento do fogo de acordo com o cenário de perigo

O modelo de baixo perigo foi desenvolvido utilizando o cenário de umidade D4 e com base no percentil de $10 \%$ do valor da carga de material combustível, espessura do leito e velocidade do vento. O 
modelo de médio perigo foi desenvolvido com base na média dos valores da carga de material combustível, espessura do leito e velocidade do vento. Nesse modelo, o cenário de umidade utilizado foi o D3. Já o modelo de alto perigo foi desenvolvido com base no cenário de umidade D2 e no percentil de 90\% dos valores da carga de material combustível, espessura do leito e velocidade do vento (Tabela 5).

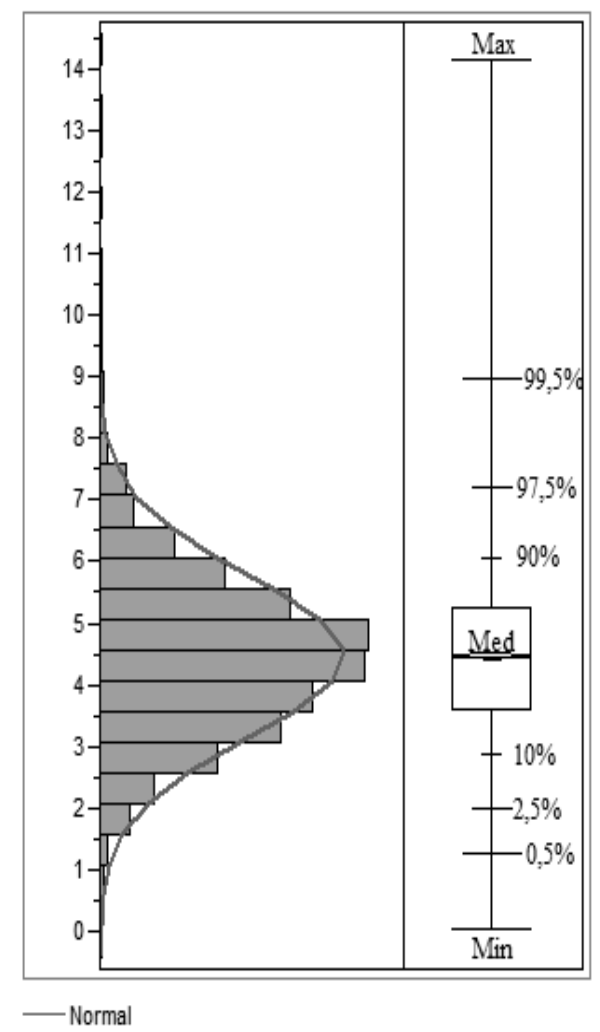

Figura 2. Distribuição da velocidade do vento, indicando o valor médio, os percentis e a respectiva linha normal, com base nos valores da estação meteorológica Salgado, localizada no município de Inhambupe, Bahia.

Figure 2. Wind speed distribution indicating the mean value, the percentiles and the normal line based on the Salgado meteorological station data, located in the Inhambupe County, Bahia.

No primeiro cenário, de baixo perigo, a carga de material combustível e a espessura do leito apresentam valores demasiadamente pequenos para propagarem o fogo uniformemente. A velocidade máxima de propagação $(0,1 \mathrm{~m} / \mathrm{min})$, o baixo comprimento das chamas $(0,1 \mathrm{~m})$ e a baixa intensidade da linha do fogo $(1 \mathrm{~kW} / \mathrm{m})$ indicam que o fogo pode ser facilmente controlado por pessoas utilizando-se apenas equipamentos de mão. Em função da baixa continuidade de material combustível, pode acontecer de o fogo extinguir-se por si só, caso haja áreas sem continuidade horizontal.

No cenário de médio perigo, percebe-se que o fogo ainda é suficientemente pequeno e que pode ser contido por pessoas utilizando apenas equipamentos de mão, como bombas de água ou abafadores. Maiores cuidados, entretanto, são necessários com relação ao cenário de baixo perigo. Recomenda-se a utilização de equipamentos básicos de segurança, como máscaras respiratórias com filtro de ar, para evitar a inalação demasiada de fumaça, além de luvas, óculos de segurança e traje adequado.

No modelo de alto perigo, o fogo é demasiadamente intenso para o combate direto utilizando-se apenas equipamentos de mão. Recomenda-se, portanto, a utilização de equipamentos de grande porte, como caminhões com bombas de água, para molhar o material combustível, e tratores ou escavadeiras para a realização de aceiros. É importante que o combate seja realizado rapidamente, já que, de acordo com McArthur (1967), a intensidade do fogo está acima do limite máximo (347 kW/m) para danos aceitáveis em florestas comerciais de eucalipto, causando a morte da maioria das árvores. 
Tabela 5. Variáveis de entrada utilizadas para a simulação do comportamento do fogo nos cenários de baixo, médio e alto perigo em povoamentos de eucalipto no litoral norte da Bahia, e suas respectivas variáveis de saída.

Table 5. Inputs used for the high, mean and low danger scenario for fire simulation in Eucalyptus plantations of the Bahia north coast and respective outputs.

\begin{tabular}{|c|c|c|c|}
\hline Variáveis & Baixo perigo & Médio perigo & Alto perigo \\
\hline \multicolumn{4}{|c|}{ Variáveis de entrada } \\
\hline Carga do material combustível de $1 \mathrm{~h}$ (t/ha) & 2,93 & 8,03 & 16,13 \\
\hline Carga do material combustível de $10 \mathrm{~h}$ (t/ha) & 1,20 & 2,74 & 5,05 \\
\hline Carga do material combustível de 100 h (t/ha) & 0,00 & 0,17 & 0,21 \\
\hline Carga do material combustível vivo herbáceo (t/ha) & 0,00 & 0,29 & 0,56 \\
\hline Carga do material combustível vivo lenhoso (t/ha) & 0,00 & 0,08 & 0,10 \\
\hline Espessura do leito (m) & 0,02 & 0,0567 & 0,109 \\
\hline Teor de umidade do material combustível de $1 \mathrm{~h}(\%)$ & 12 & 9 & 6 \\
\hline Teor de umidade do material combustível de $10 \mathrm{~h}(\%)$ & - & 10 & 7 \\
\hline Teor de umidade do material combustível de $100 \mathrm{~h}(\%)$ & - & 11 & 8 \\
\hline Teor de umidade do material combustível vivo herbáceo (\%) & - & 90 & 60 \\
\hline Teor de umidade do material combustível vivo lenhoso (\%) & - & 120 & 90 \\
\hline Velocidade do vento $(\mathrm{km} / \mathrm{h})$ & 2,86 & 4,45 & 6,07 \\
\hline \multicolumn{4}{|c|}{ Variáveis de saída } \\
\hline Velocidade máxima de propagação (m/min) & 0,1 & 0,4 & 1,4 \\
\hline Comprimento das chamas (m) & 0,1 & 0,5 & 1,2 \\
\hline Intensidade da linha do fogo $(\mathrm{kW} / \mathrm{m})$ & 1 & 58 & 411 \\
\hline
\end{tabular}

\section{Discussão do comportamento do fogo}

Em função das dificuldades envolvendo o procedimento de construção de modelos customizados de material combustível e na utilização de softwares que simulam o comportamento do fogo, não é comum encontrar na literatura trabalhos que utilizem essa ferramenta, sendo a maioria dos estudos realizados em países como Estados Unidos, Austrália, Canadá e alguns outros do leste europeu (WHITE et al., 2013a).

Comparando os dados obtidos através das simulações do comportamento do fogo deste trabalho com outros já publicados, percebe-se que, na maioria dos casos, a intensidade do fogo foi mais baixa. Gould et al. (2007), por exemplo, para florestas de eucalipto na Austrália com sete anos de acúmulo de material combustível, definiram, através de queimas experimentais, valores máximos de velocidade de propagação, comprimento das chamas e intensidade da linha do fogo, de $16 \mathrm{~m} / \mathrm{min}, 7,7 \mathrm{~m}$ e $4116 \mathrm{~kW} / \mathrm{m}$, respectivamente, valores aproximadamente 10 vezes maiores que os obtidos neste estudo. White et al. (2013a) determinaram a velocidade de propagação do fogo de $12,1 \mathrm{~m} / \mathrm{min}$, o comprimento das chamas de $2,7 \mathrm{~m}$ e a intensidade da linha do fogo de $2292 \mathrm{~kW} / \mathrm{m}$ para o cenário de alto perigo em florestas arbustivas no Parque Nacional Serra de Itabaiana, Sergipe, Brasil. Fernandes (2009), para florestas de pinheirobravo em Portugal, definiu, através de queimas experimentais, velocidade máxima de propagação do fogo de $7,2 \mathrm{~m} / \mathrm{min}$ e comprimento das chamas máximo de $4 \mathrm{~m}$.

A menor intensidade do fogo na área de estudo pode ser justificada, principalmente, em função dos procedimentos de limpeza do sub-bosque comuns nos povoamentos de eucalipto da empresa Copener. O desbaste da vegetação de sub-bosque acaba por reduzir a espessura do leito, que, de acordo com Andrews (2009), é uma variável que exerce alta influência no modelo de propagação do fogo superficial de Rothermel (1972).

Entretanto, o fogo simulado nos povoamentos de eucalipto ainda costuma ser mais intenso do que em áreas de floresta tropical fechada. De acordo com White et al. (2013a), em áreas de floresta tropical no Parque Nacional Serra de Itabaiana, no cenário de perigo alto, a velocidade de propagação máxima simulada foi de $0,3 \mathrm{~m} / \mathrm{min}$, o comprimento das chamas foi de $0,3 \mathrm{~m}$ e a intensidade da linha do fogo foi de $21 \mathrm{~kW} / \mathrm{m}$, enquanto que no cenário de médio perigo o fogo não teve intensidade suficiente para consumir o material combustível (velocidade de propagação $0,0 \mathrm{~m} / \mathrm{min}$ ). 


\section{CONCLUSÕES}

- Os povoamentos de eucalipto apresentaram em média 11,31 t/ha de material combustível, sendo a classe MS1 predominante, compondo 70\% do total. A espessura do leito apresentou um valor médio de $5,67 \mathrm{~cm}$, portanto a densidade média do material combustível estimada foi de $19,84 \mathrm{~kg} / \mathrm{m}^{3}$. A velocidade do vento média registrada na área de estudo foi de $4,45 \mathrm{~km} / \mathrm{h}$.

- De acordo com as simulações, apenas no cenário de alto perigo é essencial a utilização de equipamentos de grande porte, como caminhões com bombas de água para molhar o material combustível e tratores ou escavadeiras para a realização de aceiros. Nos demais cenários, o fogo pode ser apagado por pessoas atacando a sua frente e utilizando-se apenas de equipamentos de mão.

\section{AGRADECIMENTOS}

À FAPITEC/SE, pela bolsa de estudos concedida ao primeiro autor.

\section{REFERÊNCIAS}

ANDREWS, P. L. BehavePlus fire modeling system, version 5.0: variables. Fort Collins: USDA Forest Service, Rocky Mountain Research Station, 2009. 124 p. (General Technical Report).

ANDREWS, P. L.; BEVINS, C. D.; SELI, R. C. BehavePlus fire modeling system version 2.0 user's guide. Ogden: USDA Forest Service, 2003. 133 p. (General Technical Report).

BARRETT, T. M.; JONES, J. G.; WAKIMOTO, E. R. H. Forest service spatial information use for planning prescribed fires. Western Journal of Applied Forestry, v. 15, n. 4, p. 200 - 207, 2000.

BROOKS, M. L.; D’ANTONIO, C. M.; RICHARDSON, D. M.; GRACE, J. B.; KEELEY, J. E.; DITOMASO, J. M.; HOBBS, R. J.; PELLANT, M.; PYKE, D. Effects of invasive alien plants on fire regimes. BioScience, Reston, v. 54, n. 7, p. 677 - 688, 2004.

BROWN, J. K.; OBERHEU, R. D.; JOHNSTON, C. M. Handbook for inventorying surface fuels and biomass in the interior west. Ogden: USDA Forest Service, 1982. 48 p. (General Technical Report).

BURGAN, R. E.; ROTHERMEL, R. C. BEHAVE: fire behavior prediction and fuel modeling system fuel subsystem. Odgen: Intermountain Forest and Range Experiment Station, 1984. 126 p.

BYRAM, G. M. Combustion of forest fuels. In: DAVIS, K. P. Forest fire: control and use. New York: McGraw-Hill, 1959. p. 61-89.

FERNANDES, P. M. Examining fuel treatment longevity through experimental and simulated surface fire behaviour: a maritime pine case study. Canadian Journal of Forest Research, Birmingham, v. 39, p. 2529 - 2535, 2009.

FERNANDES, P. M.; LOUREIRO, C.; PALHEIRO, P.; VALE-GONÇALVES, H.; FERNANDES, M. M.; CRUZ, M. G. Fuels and fire hazard in blue gum (Eucalyptus globulus) stands in Portugal. Boletín del CIDEU, Huelva, v. 10, p. 53 - 61, 2011.

FINNEY, M. A. Farsite: fire area simulator-model development and evaluation. Missoula: USDA Forest Service, Intermountain Fire Sciences Laboratory, 1998, 52 p.

GILROY, J.; TRAN, C. A new fuel load model for eucalypt forest in southeast Queensland. In: Bush Fire Conference, 9., 2006, Brisbane. Proceedings... Brisbane, 2006. Paper $n^{\circ} 8$.

GOULD, J. S.; MCCAW, W. L.; CHENEY, N. P.; ELLIS, P. F.; KNIGHT, I. K.; SULLIVAN, A. L. Project Vesta-Fire in dry eucalypt forest: fuel structure, fuel dynamics and fire behavior. Perth: CSIRO Publishing, 2007, 218 p. 
HOFFMANN, W. A.; JACONIS, S. Y.; MCKINLEY, K. L.; GEIGER, E. L.; GOTSCH, S. G.; FRANCO, A. C. Fuels or microclimate? Understanding the drivers of fire feedbacks at savanna-forest boundaries. Austral Ecology, v. 37, n. 6, p. 634 - 643, 2012.

MATTHEWS, S. Effect of drying temperature on fuel moisture content measurements. International Journal of Wildland Fire, v. 19, p. 800 - 802, 2010.

MCARTHUR, A. G. Fire behavior in eucalypt forests. Canberra: Australian Forestry and Timber Bureau Leaflet, 1967. 36 p.

MISTRY, J.; BERARDI, A. Assessing fire potential in a brazilian savanna nature reserve. Biotropica, v. 37, n. 3, p. 439 - 451, 2005.

REGO, F. C.; BOTELHO, H. S. A técnica do fogo controlado. Vila Real: Universidade de Trás-osMontes e Alto Douro, 1990. 124 p.

RIBEIRO, G. A.; SOARES, R. V. Caracterização do material combustível superficial e efeitos da queima controlada sobre sua redução em um povoamento de Eucalyptus viminalis. Revista Cerne, Lavras, v. 4, n. 1, p. $58-72,1998$.

ROTHERMEL, R. C. A mathematical model for predicting fire spread in wildland fuels. Ogden: USDA Forest Service, Intermountain Forest and Range Experiment Station, 1972. 40 p. (Research Paper).

SANTOS, J. F.; SOARES, R. V.; BATISTA, A. C. Perfil dos incêndios florestais no Brasil em áreas protegidas no período de 1998 a 2002. Revista Floresta, Curitiba, v. 36, n. 1, p. 93 - 100, 2006.

SCOTT, J. H.; BURGAN, R. E. Standard fire behavior fuel models: a comprehensive set for use with Rothermel's surface fire spread model. Fort Collins: USDA Forest Service, Rocky Mountain Research Station, 2005. 72 p. (General Technical Report).

SOARES, R. V.; BATISTA, A. C. Incêndios florestais: controle, efeitos e uso do fogo. Curitiba, 2007. $264 \mathrm{p}$.

SOCIEDADE BRASILEIRA DE SILVICULTURA (SBS). Dados estatísticos sobre a produção nacional de eucalipto. Disponível em: <http://www.sbs.org.br/secure/estatisticas.htm>. Acesso em: 20/04/2009.

SOUZA, L. J. B.; SOARES, R. V.; BATISTA, A. C. Modelagem do material combustível superficial em povoamentos de Eucalyptus dunnii, em Três Barras, SC. Revista Cerne, Lavras, v. 9, n. 2, p. 231 - 245, 2003.

STANGERLIN, D. M.; HENNERICH, M.; GOMES, F. A.; CALEGARI, L.; MELO, R. R.; GATTO, D. A. Quantificação do material combustível acumulado na serapilheira de uma floresta de Eucalyptus grandis. In: Congresso de Iniciação Científica da UFPEL, 16., 2007, Pelotas. Anais... Pelotas, 2007.

TOLHURST, K. G.; CHENEY, N. P. Synopsis of the knowledge used in prescribed burning in Victoria. East Melbourne: Department of Natural Resources and Environment, 1999. 97 p.

WELLS, G. The Rothermel fire-spread model: still running like a champ. Fire Science Digest, v. 2 , p. 1 $12,2008$.

WHITE, B. L. A.; RIBEIRO, A. S.; RIBEIRO, G. T.; SOUZA, R. M. Building fuel models and simulating their surface fire behavior in the "Serra de Itabaiana" National Park, Sergipe, Brazil. Revista Floresta, Curitiba, v. 43, n. 1, p. 27 - 38, 2013a.

WHITE, B. L. A.; RIBEIRO, G. T.; SOUZA, R. M. O uso do BehavePlus como ferramenta para modelagem do comportamento e efeito do fogo. Pesquisa Florestal Brasileira, Colombo, v. 33, n. 73, p. $73-83,2013 b$. 